\title{
CONTO DE FADAS DA LAMA: UMA DISCUSSÃO SOBRE TIPOLOGIA DE STORYTELLING
}

\author{
(Mud's fairy tale: a discussion about storytelling typology)
}

\author{
Jéssica Cristina Ceni ${ }^{1}$ \\ Universidade Federal do Paraná \\ Natália Rese ${ }^{2}$ \\ Universidade Federal do Paraná
}

\begin{abstract}
RESUMO
Discute-se nesse trabalho a prática de Storytelling como um dos recursos empregados para influenciar os significados dos impactos decorrentes de um desastre corporativo, buscando-se a preservação da imagem organizacional. O objetivo deste trabalho é analisar a tipologia do Storytelling proposta por O'Neill (2011) na produção discursiva da empresa de Mineração Samarco pós-rompimento na Barragem de Fundão. Como resultados, foram encontradas estórias construídas pela Samarco que ilustram os quatro tipos de estória propostas por O'Neill (2002). Além disso, esse trabalho reforça o papel da construção e disseminação de estórias como recurso utilizado pelas organizações em momentos de crise organizacional e recuperação de imagem.
\end{abstract}

Palavras-chave: Storytelling. Comunicação. Gestão do inesperado. Samarco. Desastre corporativo.

\begin{abstract}
This paper discusses the practice of Storytelling as one of the resources used to influence meanings regarding the impacts of a corporate disaster, in which the organization seeks to preserve its image. The purpose of this research is to analyze the typology of Storytelling proposed by O'Neill (2011) in the post-rupture discursive production of Samarco Company. As results, we found stories built by Samarco that illustrate the four types of stories proposed by O'Neill (2002). In addition, this work reinforces the role of story construction and dissemination as a resource used by organizations in times of organizational crisis and image recovery.
\end{abstract}

Keywords: Storytelling. Communication. Managing the unexpected. Samarco. Corporate disaster

\section{RESUMEN}

Este documento analiza la práctica de Storytelling como uno de los recursos utilizados para influir en los significados con respecto a los impactos de un desastre corporativo, en el que la organización busca preservar su imagen. El propósito de esta investigación es analizar la tipología de Storytelling propuesta por O'Neill (2011) en la producción discursiva de la Compañía Samarco post-ruptura. Como resultado, encontramos historias construidas por Samarco que ilustran los cuatro tipos de historias propuestas por O'Neill (2002). Además, este trabajo refuerza el papel de la construcción y difusión de historias como un recurso utilizado por las organizaciones en tiempos de crisis organizacional y recuperación de imagen.

Palabras clave: Storytelling. Comunicación. Gestión de lo inesperado. Samarco. Desastre corporativo.

\footnotetext{
1 Doutoranda no Programa de Pós-Graduação em Administração (PPGADM) da Universidade Federal do Paraná UFPR - Campus Jardim Botânico; jessica.ceni@ufpr.br

2 Docente no Programa de Pós-Graduação em Administração (PPGADM) da Universidade Federal do Paraná - UFPR Campus Jardim Botânico; resenati@gmail.com
} 
Recebido em: abril 2019

Aceito em: novembro 2019

DOI: $10.26512 /$ les.v20i2.24192

\section{INTRODUÇÃO}

“O furação Katrina, o tsunami na Ásia, o escândalo da Enron, os ataques terroristas de 11 de setembro, as bombas em Londres, são desastres de larga escala, e que testaram a estabilidade de nossas organizações". (WEICK; SUTCLIFFE, 2007). Consoante aos desastres aludidos por Weick e Sutcliffe (2007), deparamo-nos com outro no contexto brasileiro: o rompimento na barragem de Fundão, de responsabilidade da Samarco Mineração. Tal desastre corporativo é considerado na literatura "como o maior desastre socioambiental ocorrido no Brasil e um dos maiores relacionados à mineração no mundo". (MODENA; HELLER, 2016).

Os desastres são caracterizados, segundo Mcfarlane e Norris (2006, p. 4), por eventos "potencialmente traumáticos, vivenciados coletivamente, que possuem um início abrupto, são delimitados pelo tempo, e podem ser atribuídos a causas naturais, tecnológicas ou humanas”. As organizações ao se depararem com eventos dessa natureza passam, de acordo com Bundy et al. (2016), por períodos chamados de crises organizacionais, e que por sua vez, requerem de sua parte um intenso trabalho de construção de sentido. Os autores argumentam que a gestão de crises organizacionais envolve "moldar percepções" para que consiga prevenir, resolver e crescer a partir de crise, levando em consideração tanto a si quanto todos os envolvidos.

Faz-se relevante observar que se compreende a organização não como algo capaz de agir como entidade autônoma, mas como uma coletividade organizada. Ainda que organizada, reconhecese sua característica inerentemente contraditória. Não obstante, os desastres e as crises parecem ser a radicalização da natureza contraditória do movimento organizacional e, ao ocorrerem, desencadeiam organizacionalmente uma ruptura com os sentidos anteriormente compartilhados entre todos os membros organizacionais e com a estabilidade que tal situação sustenta. Muito além disso, os desastres e crises, dados seus amplos impactos para além dos limites organizacionais, desencadeiam também uma crise de legitimidade. Entende-se aqui que as estórias, alicerçadas nas intenções organizacionais, desempenharão um papel relevante para a retomada da posição de "tradutora" da organização em relação a sua própria atividade.

Baseado nesse aspecto, uma forma de direcionar os sentidos relativos aos impactos decorrentes de um desastre frente à imagem organizacional relaciona-se à prática de Storytelling, isto 
é, o ato de contar estórias. ${ }^{3}$ Em vista de que na construção do storytelling existe a escolha de palavras, do estilo e do meio em que esta será disseminada. Kopp et al. (2011) argumentam que as estórias organizacionais podem ter diferentes níveis de impacto e utilidade. É a partir desse argumento que O’Neill (2002) desenvolve um framework referente a tipologia do storytelling organizacional. Para o autor há quatro tipos diferentes de estórias: a estória descritiva; a estória anedótica; a estória de script e, por fim, a estória épica.

As estórias têm papel inquestionável na constituição do homem como ser social. Fisher (1984) apresenta a concepção de homem como homo narrans: para dar sentido à sua vida - nas dimensões de ações, práticas, criações, ficções - os homens envolvem-se em elaborações de estórias, capazes de articular o sentido que garante plausibilidade à sua existência. Assim as narrativas humanas (presentes em todas as dimensões de sua existência) são tanto históricas quanto situacionais, carregando consigo os elementos da produção das condições humanas de existência e também os direcionamentos interpretativos das situações. Compreender, portanto, "o sentido e o significado da vida em todas as suas dimensões requer a compreensão da estrutura narrativa que a acompanha" (FISHER, 1984, p. 3). Desse ponto de vista, a estórias carregam consigo os dilemas onipresentes a respeito do bem e do mal, e quando fala a respeito dos contos de fadas, Bettleheim (2002, p. 34) afirma que "Todas [as estórias tradicionais dos contos de fada] foram modificadas pelo que o contador pensava ser de maior interesse para os ouvintes, pelo que eram suas preocupações do momento ou os problemas especiais de sua época".

Nesse contexto, a discussão do "conto de fadas da lama" que aqui se coloca carrega consigo esse entendimento: na construção da versão apresentada pela Samarco, a onipresença do "mal" na disputa com o "bem", vence - discursivamente - a luta aquele que consegue demarcar seu papel heroico, evocado pela versão que se é capaz de contar, que não carrega consigo só elementos de "ficção", mas muito mais da elaboração intencionada das práticas, atividades e histórias cotidianas, afinal como narrativamente apresenta Calvino na obra Cidades Invisíveis, sobre a cidade de Olívia, “A mentira não está no discurso, mas nas coisas” (CALVINO, 1990, p. 59).Compreendido dessa maneira, um caso frutífero para análise da tipologia proposta por O’Neill, a qual captura esses movimentos de elaboração intencionada do sentido que se deseja apresentar, figura a empresa de

\footnotetext{
${ }^{3}$ Apesar do fato de que a palavra "estória" caiu em desuso no idioma do português brasileiro (de acordo com os dicionários Aurélio e Houaiss), admitindo-se que a palavra "história" admite todas as acepções da palavra (que segundo o dicionário Aurélio significa "Narração escrita dos fatos notáveis ocorridos numa sociedade em partilhar ou em várias" é é, portanto, diferente da palavra estória - Story do inglês - a qual é utilizada neste trabalho como recurso de pesquisa e segundo o dicionário Cambridge significa "descrição, tanto verdadeira como imaginária, de uma série de eventos conectados"), como pesquisadores, no contexto desta pesquisa, entendemos que a palavra "estória" denota um sentido diferente daquele evocado pela palavra "história": pretende-se demarcar a ideia de que o que se discute aqui são as narrativas, versões, construções discursivas que intencionalmente direcionam um sentindo, motivo pelo qual usa-se propositadamente a palavra "estória".
} 
Mineração Samarco, pois, a partir do rompimento a empresa perdeu sua licença social ${ }^{4}$ para operar, e consequentemente, com sua imagem organizacional em crise apresenta um storytelling pós-desastre cujo objetivo é de elaborar a contação sobre os impactos do evento em relação a sua imagem organizacional, e assim, obter novamente a licença social para voltar a operar.

Em síntese o objetivo deste trabalho é analisar a tipologia do Storytelling proposta por O’Neill (2011) na produção discursiva da empresa de Mineração Samarco pós-rompimento na Barragem de Fundão.

\section{GeSTÃo do InESPERAdo E A TiPOlOGIA do STORYTELling ORgANizACIONAL}

A todo o momento, as organizações em um contexto dinâmico e de incertezas, são bombardeadas por eventos inesperados que podem ou não se concretizar. De acordo com Weick e Sutcliffe (2007), um evento inesperado pode tomar três formas: a primeira está relacionada a quando um evento esperado não acontece, ou seja, falha em acontecer, já a segunda ocorre quando um evento não esperado acontece, mas prévio a ele já existiam suspeitas de que este poderia acontecer, e por fim, a última forma corresponde a um evento que não havia sido pensado antes, mas que se concretizou.

É sabido que os eventos inesperados desafiam a capacidade de resiliência das organizações, conformem pontuam Weick e Sutcliffe (2007). Do ponto de vista da análise deste trabalho, os eventos inesperados nascem da própria natureza contraditória das organizações e as rupturas existentes são resultado da radicalização de tais contradições e da ação cerimonial das organizações em relação às suas responsabilidades, para além da eficiência técnica.

Nesse contexto, as organizações quando se deparam com eventos inesperados e ao veremse responsáveis por um desastre corporativo, passam por períodos chamados de crises organizacionais que, por sua vez, geram a necessidade por parte da organização em ter gestores capazes de minimizar as incertezas e os impactos decorrentes (BUNDY et al., 2016).

Com base nesses aspectos, Weick e Sutcliffe (2007) ressaltam a existência de organizações mais capazes de superar e "gerenciar" o inesperado, sendo caracterizadas como "organizações de alta reabilitação" (HRO - High Reability Organization). Para os autores, essas organizações apresentam uma forma de organizar que reduz os impactos do evento inesperado sobre si mesma, na medida que apresentam determinadas características que estão diretamente relacionadas com a capacidade da

\footnotetext{
${ }^{4}$ A licença social, da qual a Samarco tinha posse, constitui-se da aprovação da comunidade local em relação a suas operações, e, portanto, está diretamente ligada à sua imagem e legitimidade.
} 
organização em prever possíveis falhas ou eventos inesperados, e ainda ao se organizarem dessa maneira, adquirem maior capacidade em prevenir esse tipo de evento.

Mesmo que uma organização apresente determinadas características apresentadas por Weick e Sutcliffe (2007), tornando-se organizações de alta reabilitação, esta pode vir a ser responsável por um evento inesperado ou um desastre corporativo. Quando isso ocorre, muitas vezes os impactos decorrentes não envolvem apenas a organização, mas também seus stakeholders e até mesmo a sociedade como um todo. Por essa razão espera-se que a organização responda por seus atos e solucione a causa e o porquê daquele evento ter acontecido.

Em vista disso, quando um evento inesperado se concretiza, a organização responsável passa a ser vista de outra forma por parte dos seus funcionários, clientes, fornecedores e a sociedade, e, portanto, existe uma ruptura severa sobre a imagem e a legitimidade da organização responsável pelo desastre. Portanto, discute-se aqui que o storytelling ${ }^{5}$ pode constituir uma prática a qual a organização adota tentando direcionar os sentidos relativos à atuação organizacional diante do desastre desencadeado por ela, buscando assim restaurar sua imagem, reputação e legitimidade organizacional.

No que diz respeito às pesquisas empíricas dentro dos estudos organizacionais, observa-se que o storytelling tem sido frequentemente considerado como uma prática estratégica relevante (DE LA VILLE; MOUNOUD, 2015; ROULEAU, 2015; SONENSHEIN, 2010). Alguns exemplos são o papel que desempenham frente à reputação organizacional (MITTINS et al., 2011), a sua utilização como ferramenta estratégica em situações de crises (KOPP et al., 2011) e na recuperação da imagem organizacional. (VALDEBENITO, 2013)

Além disso, "as estórias podem aliviar a ansiedade e melhorar a capacidade das organizações em navegar pelas dificuldades" (MITTINS et al., 2011, p. 418). Sobre mesmo argumento, Kopp et al. (2011, p. 376) pontuam que as estórias têm um papel essencial durante períodos de crises organizacionais, que se caracterizam pelos eventos prejudiciais ou períodos de mudança que podem vir afetar os interessados da organização - stakeholders - como também a sua própria reputação. Além disso, os autores descrevem que as crises são inerentemente narrativas, e assim, o storytelling tende a ser um "antídoto" eficaz à perda de sentido que geralmente acompanha os movimentos de crise.

Como se pode notar quando a organização adota o storytelling como um mecanismo de comunicação objetivando tratar dos impactos decorrentes de um evento inesperado em relação a sua

\footnotetext{
${ }^{5}$ Conceituado nesse trabalho a partir de Søderberg (2003) e, portanto, caracterizado como um ato comunicativo - oral ou escrito - relacionado a um evento particular que ocorreu sobre o tempo, e que, logo, toda estória possui um caráter temporal.
} 
reputação, fica evidente que escolha das palavras, da entonação da voz, o estilo e o meio pelo qual a estória construída pela organização é comunicada se caracterizam como aspectos relevantes, tendo em vista que as estórias organizacionais podem ter diferentes níveis de impacto e utilidade (KOPP et al., 2011). À vista disso, O’Neill (2002) desenvolveu um framework referente à tipologia do storytelling organizacional. O autor estabelece a existência de quatro tipos diferentes de estórias, levando em consideração sua relação ao nível de "cor", conceito relacionado aos elementos dramatúrgicos presentes, como a utilização de detalhes vívidos, ou, por exemplo, se o enredo apresenta elementos românticos, heróicos ou de comédia e o nível de engajamento (fulfilment), que segundo o autor está relacionado à adequação e engajamento da estória frente ao objetivo almejado.

Dessa maneira, O’Neill estabelece a estória descritiva (descritive story); a estória anedótica (anecdotal story); a estória de script (script story) e, por fim, a estória épica (epic story), conforme o framework da Figura 1. Além disso, O’Neill (2002) ressalta que é o narrador da estória que possui o controle sobre o quanto de "cor" colocará. Dessa maneira, a presença de elementos dramatúrgicos da história pode aumentar ou diminuir ao longo do tempo a partir da moderação do narrador frente ao nível de engajamento obtido. Para o autor, o nível de engajamento representa o nível de satisfação e acolhimento referente à estória por parte de quem a escuta e a co-constrói, na medida em que em que a interpreta, gera significados ao seu redor.

Figura 1 - Tipologia do Storytelling Organizacional

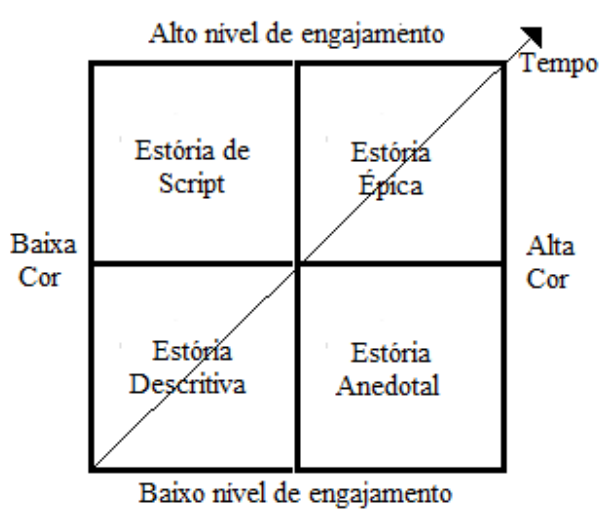

Fonte: O’Neill (2002, p. 11).

Conforme a representação de O’Neill (2002), a estória descritiva se fundamenta sobre poucos elementos dramatúrgicos e tem baixa capacidade de engajamento. Elas são caracterizadas pelas formas mais básicas de estórias e estão direcionadas a aspectos relevantes de um momento bastante específico na organização. Além disso, possuem baixa duração, sendo dificilmente recontadas, e à vista disso possuem pouco impacto estratégico na organização. 
De outro lado, a estória anedotal apresenta alta "cor" e baixa capacidade de engajamento, porém, o engajamento é maior que a estória descritiva. O’Neill (2002) descreve que esse tipo de estória usualmente se fundamenta sobre elementos que remetem à comédia, tragicidade ou ironia. Sendo um tipo de estória que satisfaz o próprio narrador ao passo que a conta, esta sobrevive por um tempo moderado na organização.

Em sequência, O’Neill (2002), ao abordar a estória de script, argumenta que mesmo possuindo poucos elementos dramatúrgicos, esse tipo de estória costuma durar um tempo moderadamente longo na organização. São estórias utilizadas em situações específicas da organização que costumam ocorrer frequentemente. Apesar de sobreviver mais tempo dentro da organização, esse tipo de estória possui impacto estratégico limitado.

Em relação ao último tipo, a estória épica é considerada como a mais apropriada em momentos de crise organizacional a partir de Kopp et al. (2011). De acordo com O’Neill (2002, p. 14), esta se caracteriza como uma estória "rica em elementos cômicos, trágicos ou heroicos", sendo um exemplo, a construção do storytelling por parte de um líder organizacional quando este tem como objetivo superar grandes dificuldades ou uma grande crise organizacional. É com base nesse tipo de estória que Kopp et al. (2011) argumentam que o storytelling pode ser um antídoto eficaz frente aos momentos de crises organizacionais. Tendo isso em vista, a estória épica alcança um engajamento maior e, portanto, possui grande impacto estratégico na organização.

Com base na tipologia do storytelling, o quadro 1 apresenta de maneira resumida os tipos das estórias e as características principais.

Quadro 1 - Características dos tipos de estória

\begin{tabular}{|c|c|}
\hline Tipo da estória & Características \\
\hline Estória descritiva & $\begin{array}{l}\text { - } \\
\text { - } \\
\text { - } \\
\text { - É pria incertezassageira (Não existe por muito tempo). } \\
\text { - } \quad \text { Impacto limitado. }\end{array}$ \\
\hline Estória Anedotal & $\begin{array}{l}\text { - } \quad \text { Divertida (Amusing and entertaining). } \\
\text { - } \quad \text { Apresenta elementos de comédia, heroísmo, tragicidade ou ironia. } \\
\text { - } \quad \text { Norada para racionalizar um comportamento ou evidenciar importância de alguém. } \\
\text { - }\end{array}$ \\
\hline Estória de Script & $\begin{array}{l}\text { - } \quad \text { Tem duração temporal moderadamente longa na organização. } \\
\text { - } \quad \text { Busca minimizar incerteza e estresse. } \\
\text { - } \quad \text { É recontada com regularidade. }\end{array}$ \\
\hline Estória Épica & $\begin{array}{l}\text { - } \quad \text { Rica em elementos heroicos e trágicos. } \\
\text { - } \quad \text { Busca superação. } \\
\text { - } \quad \text { Sobrevive por longos períodos de tempo. } \\
\end{array}$ \\
\hline
\end{tabular}


Um exemplo empírico de uma estória épica é o da empresa Enron que declarou falência em dezembro de 2001 e foi uma das maiores falências da história até aquela época nos Estados Unidos (AILON, 2015). Nesse sentido, Boje e Rosile (2003, p. 86) pontuam que o caso da Enron "é mais do que uma tragédia, é um teatro épico", e mencionam que a organização na busca de se posicionar sobre a queda brusca das suas ações, apresentava uma estória de procura pela causa e do porquê do desastre ter acontecido, ao evocar elementos clássicos do drama trágico, a falha trágica do herói (que causa tanto sucesso como fracasso) e arrogância.

Outro exemplo relacionado se encontra na pesquisa de Valdebenito (2013). O autor busca analisar o discurso criado por uma organização chilena durante um período de recuperação da imagem organizacional, em virtude da empresa estar envolvida em um escândalo corporativo. Como resultado, o autor evidenciou a exploração estratégica de recursos léxico-gramaticais e sociopragmáticos por parte dos comunicadores corporativos, caracterizados pela utilização de práticas discursivas antiéticas durante a disseminação do storytelling construído na mídia, como declarações contraditórias ou ambíguas, negação da responsabilidade frente ao escândalo, transferência de culpa, passividade, e em conclusão, o autor relata que houve impacto positivo sobre a estratégia de negação utilizada pela empresa.

Observa-se que a utilização do storytelling em momentos de crise organizacional compõe um mecanismo de comunicação bastante explorado para recuperação da imagem e legitimidade organizacional. Porém, em vista de que existem mais de um tipo de estória cujo emprego ocasiona diferentes impactos em relação aos movimentos organizacionais, torna-se relevante e revelador compreender de maneira mais profunda de que forma a tipologia proposta por O’Neill se apresenta empiricamente nos movimentos de storytelling desenvolvidos pelas organizações.

\section{Abordagem Metodológica}

Em vista do objetivo dessa pesquisa, a abordagem mais adequada para seu alcance é a abordagem qualitativa. Segundo Stake (2010), esta abordagem é caracterizada como interpretativa, baseada na experiência, situacional e personalista. Em outras palavras, existe o reconhecimento de que os significados são subjetivos e que esses podem ser observados a partir de visões divergentes e, ademais, enfatiza-se a orientação a uma situação particular e única, e que, consequentemente se traduz em uma abordagem baseada na busca pela unicidade e diversidade ao invés de comunalidade.

A pesquisa foi desenvolvida por meio de estudo de caso único, aqui representado pela empresa brasileira de mineração Samarco, a qual foi responsável pelo rompimento na barragem de Fundão em 5 de novembro de 2015, em Mariana - Minas Gerais. Nesse contexto, Stake (2000) 
identifica três tipos de estudo de caso: o intrínseco, o instrumental e o coletivo. Nessa pesquisa, o estudo de caso se caracteriza tanto como intrínseco quando como instrumental, uma vez que o caso estudado, pela relevância e abrangência, tornou-se um objeto rico de estudo, ao mesmo tempo que ao estudá-lo é possível que os elementos que o constituem sejam relevantes para compreender (e quiçá prevenir) situações organizacionais resultantes das práticas contraditórias como as desenvolvidas pela Samarco.

Além disso, Stake (2000) argumenta que o pesquisador, ao definir o método de coleta de dados, deve considerar o ajustamento à problemática de pesquisa e a estratégia adotada. Assim, esta pesquisa é baseada em dados secundários e como posicionamento os dados foram coletados no site da empresa de mineração

Quadro 2 - Fonte dos dados

\begin{tabular}{|l|l|c|}
\hline \multicolumn{1}{|c|}{ FONTE } & \multicolumn{1}{|c|}{ DADOS } & $\begin{array}{c}\text { TOTAL DE } \\
\text { DADOS } \\
\text { COLETADOS }\end{array}$ \\
\hline $\begin{array}{l}\text { 1. Site da Samarco } \\
\text { (www.samarco.com })\end{array}$ & $\begin{array}{l}307 \text { arquivos correspondentes a 9 arquivos gerais do site (22 } \\
\text { páginas); 5 relatórios (333 páginas); 1 termo de transação e } \\
\text { ajustamento de conduta (139 páginas); 44 Press Releases (96 } \\
\text { páginas); 248 notícias (303 páginas). }\end{array}$ & \\
\hline
\end{tabular}

Fonte: Elaboração própria.

Os dados coletados correspondem a todo material publicado no site da Samarco referente ao período de 5 de novembro de 2015, data do rompimento na Barragem de Fundão, até 30 de agosto de 2017, data da coleta. No que diz respeito à análise, optou-se em primeiro momento pela realização da análise de conteúdo.

No que concerne à análise, todos os dados foram transferidos para o software Atlas.ti. A análise foi feita com base em uma leitura flutuante, cujo objetivo foi o de extrair as informações necessárias como a) tipo do documento e como este se apresenta; b) tema geral do texto; c) mensagem geral.

Sendo conduzida na forma de linha do tempo, na análise foi possível observar os desdobramentos e direcionamentos do conteúdo (conforme quadro 3) disseminado pela Samarco ao longo do tempo, data da coleta. Com base na linha do tempo construída e observando a constituição das diversas estórias no período houve, assim, a possibilidade de analisar as estórias mais emblemáticas e de que forma estas se relacionam com a tipologia proposta por O’Neill. Obviamente, ressalta-se ainda que a tipologia constitui uma abstração e por essa razão nem sempre foi possível encontrar exatamente as mesmas características propostas pelo autor.

Quadro 3 - Direcionamento do conteúdo: as estórias construídas 


\begin{tabular}{|c|c|}
\hline Período & Direcionamento do conteúdo: Estórias construídas \\
\hline $\begin{array}{l}\text { 05 de Novembro de } 2015 \text { a } 31 \text { de Janeiro } \\
\text { de } 2016\end{array}$ & $\begin{array}{ll}\text { - } & \text { Pedido de desculpas } \\
\text { - } & \text { Somos comprometidos e honestos } \\
\text { - } & \text { Potabilidade da água } \\
\end{array}$ \\
\hline 01 de Fevereiro a 30 de Abril de 2016 & - $\quad$ Atuação social na comunidade \\
\hline 01 de Maio a 31 de Julho de 2016 & $\begin{array}{l}\text { - Processo de reconstrução dos distritos impactados e participação } \\
\text { da comunidade }\end{array}$ \\
\hline 01 de Agosto a 31 de Outubro de 2016 & - $\quad$ O início da operacionalização da Fundação Renova \\
\hline $\begin{array}{l}01 \text { de Novembro de } 2016 \text { a } 31 \text { de Janeiro } \\
\text { de } 2017\end{array}$ & $\begin{array}{l}\text { - Um ano do rompimento na Barragem de Fundão } \\
\text { - } \quad \text { As ações socioculturais }\end{array}$ \\
\hline 01 de Fevereiro a 31 de Abril de 2017 & $\begin{array}{l}\text { - } \quad \text { A volta das operações da Samarco } \\
\text { - } \quad \text { Os impactos econômicos e nossa inoperação } \\
\end{array}$ \\
\hline 01 de Maio a 31 de Agosto de 2017 & $\begin{array}{l}\text { - } \quad \text { Samarco: "Queremos voltar a operar" } \\
\text { - } \quad \text { Os períodos de Layoff } \\
\text { - } \quad \text { A Legitimidade da Fundação Renova }\end{array}$ \\
\hline
\end{tabular}

Fonte: Elaboração própria.

A partir do direcionamento do conteúdo encontrado, foram escolhidos os documentos emblemáticos de cada período. E então em um segundo momento foi realizada uma análise narrativa, baseada na abordagem interacional narrativa de Shuman (2012). Os pontos observados para relevar a estrutura narrativa foram: i) tellability, relacionado ao conteúdo e contexto; ii) propriedade e posicionamento, relacionado a quem fala e como este se coloca; iii) pronome pessoal e formato de texto, ou seja, como o texto se apresenta; iv) intertextualidade e narrativa dialógica, relacionadas à apresentação dos interesses divergentes; v) categoria social e política, isto é, pessoas que fazem parte da narrativa e, por fim, vi) mote narrativo, isto é, o que fica para além de tudo.

\section{Os Tipos de Storytelling Na ProduÇão Discursiva da SAMarco Pós-Rompimento}

No dia 05 de novembro de 2015, a aparente estabilidade de uma organização que detinha licença social para operar, que era estimada pela comunidade local e considerada responsável pela economia de toda uma região, se diluiu em um mar de lama, e assim começa o "conto de fadas da lama" contado pela Samarco. O rompimento na Barragem de Fundão, de responsabilidade da empresa de mineração Samarco, causou diversos impactos quando organização deixou escorrer 34 milhões de metros cúbicos de lama no Rio Doce, que também incluía rejeitos de mineração (WANDERLEY; GONCALVES; MILANEZ, 2016).

Tal evento "inesperado" é considerado na literatura "como o maior desastre socioambiental no Brasil e uns dos maiores relacionados a mineração do mundo" (MODENA; HELLER, 2016). Como consequência, a Samarco, no período pós-rompimento, se deparou com sua imagem organizacional comprometida e legitimidade abalada, fato que é evidenciado pela perda de sua licença social. 
Então, desde o rompimento a organização publicou de maneira constante notícias, press releases e documentos em geral em seu site, referentes ao desastre e no que diz respeito a sua tomada de decisões, ações realizadas e sua participação em termos com diversas agências governamentais e os governos de Minas Gerais e do Espírito Santo. Aquilo que pode parecer, em um primeiro momento, como uma "inocente" prestação de contas, no entanto, parece articulado para que o final dessa estória seja "feliz" para a organização que figurou como a grande vilã; é como se o lobo mau, após ter feito tudo o que fez com a vovozinha, recebesse novamente um convite para jantar na casa da família da Chapeuzinho Vermelho. ${ }^{6}$

Como se pode observar, o caso escolhido figura como pertinente para análise dos tipos de estória propostos por O’Neill (2002), afinal, a organização tida como responsável pelo desastre paralisou suas operações em virtude do desastre ocorrido e, portanto, a partir do rompimento, a empresa busca por meio de sua produção discursiva minimizar os impactos do incidente em relação a sua imagem e legitimidade. A partir da análise de conteúdo, foram escolhidos alguns temas abordados pela organização que exemplificam os tipos de estórias propostas por O’Neill (2002).

\section{a) A estória descritiva}

A estória descritiva possui pouco impacto estratégico na organização e costuma não ser recontada e, dessa maneira, é utilizada para descrever ou informar algo específico de determinado período. Esse tipo de estória costuma ser detalhada, tendo o poder de criar incerteza e estresse ao público a que esta é direcionada.

Um exemplo de estória descritiva construída e disseminada pela Samarco diz respeito ao tema "Potabilidade da água". Esse tema tem início em novembro de 2015, com a divulgação da notícia "Laudos garantem potabilidade da água tratada em Colatina" (SAMARCO MINERAÇÃO, 2017a) e tem continuidade no mês dezembro com mais três textos: "A água em Colatina é segura e própria para o consumo e uso doméstico" (SAMARCO MINERAÇÃO, 2017b); "Laudos do CRPM e da ANA atestam qualidade da água no Rio Doce" (SAMARCO MINERAÇÃO, 2017c); e "Samarco apoia e capacita equipes das estações de tratamento" (SAMARCO MINERAÇÃO, 2017d). A estória construída e publicada em quatro notícias busca informar sobre e descrever a potabilidade da água no município de Colatina, havendo um esforço significativo em dizer que a água disponível na região é potável e que existe efetividade em seu tratamento.

\footnotetext{
${ }^{6}$ Aqui faz-se uma referência ao famoso conto de fadas da "Chapeuzinho Vermelho", como um gancho argumentativo e metafórico relacionado à temática teórica que embasa o trabalho, como que em uma licença poética.
} 
A estória "Potabilidade da água" vai ao encontro das características descritas por O’Neill (2002) a respeito da estória descritiva. Em primeiro momento, procura-se evidenciar e mostrar detalhes a respeito da efetividade das ações organizacionais relacionadas ao tratamento da água na região de Colatina em Minas Gerais. Todavia, ao afirmarem na primeira notícia que "é comum que a água apresente odor e coloração amarela”, cria-se incerteza e estresse aos interessados - aqui representados pela população impactada pelo rompimento estabelecida na região de Colatina (SAMARCO MINERAÇÃO, 2017a).

Por conseguinte, a organização ao divulgar outra notícia tenta descrever os motivos do porque a água apresenta coloração e odor e sugere tratamento adicional aos impactados. Aqui, ao invés de minimizar as incertezas e o estresse, a Samarco piora a situação na medida em que apresenta detalhes e descrições contraditórias. Como é o caso das notícias de dezembro, em que empresa justifica a turbidez e odor da água devido ao tratamento gerar a alta dosagem do hiperclorito (SAMARCO MINERAÇÃO, 2017b), contudo, em vista de que o problema não foi resolvido, a Samarco novamente adiciona à estória que ela irá contratar equipes adicionais de tratamento, pois este ficou complexo e que "o apoio se justifica em função do aumento da turbidez da água no Rio Doce" (SAMARCO MINERAÇÃO, 2017c).

Observe-se que a Samarco, na busca de descrever e apresentar detalhes demasiadamente, acaba criando maior incerteza e estresse perante o público interessado. Além disso, esta estória é passageira e, logo, esta termina com a notícia sobre as equipes de tratamento - as quais provavelmente - deram um fim e resolveram a situação apresentada pela organização. Em suma, observa-se que essa estória tem impacto limitado direcionado apenas aos moradores da região evidenciado pela estória construída, outra característica evidenciada por O’Neill (2002). Não obstante, circunscreve-se a um momento específico, da grande narrativa construída ao longo dos dois anos pela Samarco e parece ter um claro objetivo de criar o contexto para a descrição de uma ação responsiva por parte da organização após o desastre. Se fizermos um paralelo com o conto de fadas da Chapeuzinho Vermelho, é o mesmo que descrever os aspectos da floresta, seu clima, suas cores, seus cheiros. Cria no leitor intimidade com os personagens, coloca-o dentro da estória.

\section{b) A estória anedotal (ou estória narcisista)}

A estória anedótica, conforme O’Neill (2002), possui baixo engajamento do público alvo, porém, apresenta alta “cor”, isto é, é permeada por elementos de tragicidade, comédia ou ironia. No desenvolvimento da narrativa da Samarco a respeito do rompimento da Barragem de Fundão, não se identificou a contação de uma estória anedotal, tendo em vista seu caráter divertido e permeado pelo 
humor. Evidentemente o contexto do desastre não permitia a utilização desse tipo de recurso. No entanto, analisando as características e os objetivos desse tipo de estória, observa-se que se busca com ela racionalizar um comportamento ou evidenciar importância de alguém, normalmente, a estória é sobre o próprio narrador (O’Neill, 2002). Nesse sentido, entende-se que podemos compreender no caso analisado uma variação que aqui chamaremos de "estória narcisista". Ela possui o mesmo objetivo da estória anedotal descrita por O’Neill (2002), porém, ao invés de usar as características de humor, emprega o recurso da exaltação heroica do personagem. Nesse sentindo, a estória apresentada pela Samarco é a referente aos "Impactos econômicos e a inoperação".

Essa estória é construída pela Samarco com o objetivo de informar os impactos econômicos decorrentes da sua inatividade. Os documentos que se apresentam como mais emblemáticos e ilustram tal estória é a apresentação "atemporal” presente no site da Samarco chamado "A Samarco e a economia" (SAMARCO MINERAÇÃO, 2017b) e a notícia publicada em 28 de março de 2017, intitulada "Estudo mostra impacto da paralisação da Samarco na Economia" (SAMARCO MINERAÇÃO, 2017f). É importante ressaltar aqui que essa estória permeia diversas outras, dando suporte a argumentos e principalmente um dos motivos e justificativas centrais adotadas pela empresa para reforçar a necessidade de que ela deve voltar a operar.

A respeito da estória "Impactos econômicos e a inoperação", esta se apresenta em primeira pessoa e, portanto, é sobre o próprio narrador - a Samarco - que se coloca como herói, na medida em que alude à importância econômica das suas operações para a região e para o país. Todavia, ao mesmo tempo em que apresenta seu papel heroico, a empresa reitera de maneira constante elementos trágicos, relacionados ao impacto da sua paralisação para a economia da região e do país, quando, por exemplo, afirma que "20 mil empregos podem estar em risco no próximo ano, caso a Samarco não volte a operar nos estados de Minas Gerais e Espírito Santo em 2017” (SAMARCO MINERAÇÃO, 2017f).

Em seguida, de acordo com O’Neill (2002), a estória anedótica, e no nosso caso a estória narcisista, é utilizada para evidenciar a importância de alguém, nesse contexto, observa-se esse elemento de maneira bastante clara quando ressalta-se na estória construída que a "Samarco desempenha um papel importante na economia brasileira", que sua "receita impacta principalmente no PIB de Minas Gerais e Espírito Santo” e que, ainda, “32 milhões de impostos foram pagos pela Samarco aos municípios de influencias direta no Espirito Santo em 2014 e outros R \$ 50 milhões foram destinados aos municípios de influência direta em Minas Gerais, em 2014" (SAMARCO MINERAÇÃO, 2017f).

Em suma, a estória anedotal, segundo O’Neill (2002) apresentaria maior engajamento em relação à estória descritiva, dado que busca enfatizar a importância do narrador, na medida em que este adere e apresenta elementos heroicos e de tragicidade. Subjacente a tal análise, essa estória não 
apresenta a característica do divertimento (amusing e entertaning) abordada pelo autor, mas explora, por outro lado, elementos de exaltação de um personagem autocentrado, buscando a evidenciação de detalhes que o aproximam dos dilemas e emoções daqueles que estão na posição de leitores da estória. Ora, em um contexto de crise econômica como o que se vive hoje no Brasil, trabalhar a exaltação do poder da organização de contribuir com o desenvolvimento econômico de uma comunidade (e de um país) desperta a empatia e o "colorido" que se espera ver uma estória "real".

\section{c) A estória de Script}

Diferente da descritiva e anedotal, a estória de Script permanece por períodos mais longos na organização, sendo uma estória contada com regularidade (O’NEILL, 2002). Com base nesses aspectos, a estória construída pela Samarco que ilustra esse tipo é a "Nós estamos agindo".

A estória "Nós estamos agindo" tem seu início logo após o rompimento e se estende durante todo o período analisado. A construção dessa estória ocorre por meio da disseminação de mais de 20 documentos por parte da organização, dentre eles, notícias e press releases.

Com a concretização do desastre, sucederam-se diversos impactos relacionados à população exposta, ambientais e socioeconômicos (GOVERNO DE MINAS GERAIS, 2016). Em vista disso, a organização passou a mostrar e evidenciar que efetivamente está agindo para minimizar as questões decorrentes do rompimento na Barragem de Fundão.

É nesse contexto que a estória "Nós estamos agindo" se apresenta. Um dos documentos veiculados pela Samarco figura a publicação de um mês após o rompimento, cujo título é "Fazer o que deve ser feito. Esse é o nosso compromisso" (SAMARCO MINERAÇÃO, 2017g).

Fica bastante claro que durante todo período analisado - que corresponde do dia 5 de novembro de 2015 até agosto de 2017 (período da coleta dos dados) - que a Samarco disseminou com regularidade suas ações como, também, a aderência de um discurso pautado em sua responsabilidade "em fazer o que deve ser feito".

Um dos elementos abordados por O’Neill (2002) que está presente na estória de script é o de minimizar incerteza. Esse elemento é exemplificado pelo seguinte trecho

Nós, da Samarco, reafirmamos nossa profunda consternação pelo acidente ocorrido. Já, desde o primeiro momento, mobilizamos todos os recursos disponíveis, humanos e financeiros, para atender às emergências e buscar soluções (SAMARCO MINERAÇÃO, 2017g).

Em suma, a estória de script construída pela Samarco busca reforçar continuamente, a partir de sua recorrência, o quanto a empresa está empenhando esforços para resolver os impactos a partir 
de suas ações. Fica explícito que a estória "Nós estamos agindo" busca minimizar incertezas em relação às ações desenvolvidas pela empresa e de que ela está de fato agindo. Ainda, é importante frisar que a empresa divulgou demasiadamente as mesmas ações em momentos divergentes. (SAMARCO, 2017g).

\section{d) A estória Épica}

De acordo com Kopp et al. (2011), a estória épica figura como a mais adequada, dada sua capacidade de engajamento, para os momentos de crises organizacionais. No que diz respeito a suas características, O’Neill (2002) pontua que esse tipo de estória apresenta de forma intensa elementos cômicos, trágicos ou heroicos. Ademais, o narrador é comumente, nesse tipo de estória, alguém relevante para a organização ou um líder organizacional que busca, a partir da estória, minimizar e superar momentos de crises organizacionais. Portanto, observa-se que a estória épica busca a superação, frente a um período de crise organizacional ou ainda de uma situação decorrente de um evento inesperado.

Em vista das características da estória épica, a estória disseminada pela Samarco que vai ao encontro de O’Neill, é a chamada “Queremos voltar a operar”. Essa estória teve seu início com a publicação de press release no dia 6 de maio de 2016, intitulada "Retorno das operações da Samarco é tema de audiência pública no espírito Santo" (SAMARCO MINERAÇÃO, 2017h). Contudo, sua continuidade se deu apenas no ano subsequente quando a organização publicou o press release no dia 22 de maio de 2017, "Paralisada há mais de um ano e meio, Samarco busca licenças para retomar as operações” (SAMARCO MINERAÇÃO, 2017i) e mais duas notícias, uma do dia 23 de maio de 2017, intitulada "Retomada das operações da Samarco é tema de audiência pública" (SAMARCO MINERAÇÃO, 2017j); e a outra do dia 30 de maio 2017, “Artigo: queremos voltar a operar". (SAMARCO MINERAÇÃO, 2017k).

Especificamente a notícia do dia 30 de maio de 2017, intitulada "Artigo: queremos voltar a operar", se caracteriza como a notícia mais emblemática dessa estória, a qual foi construída ao redor do tema "Queremos voltar a operar", pela Samarco. Isso decorre de a estória ter como narrador o diretor-presidente da Samarco Roberto Carvalho, o qual alude a todos os momentos que a organização vem vivenciando e atuando desde o rompimento (SAMARCO, 2017k).

Observe que um dos elementos da estória épica abordados por O’Neill et al (2002) se caracteriza por um narrador que é um membro organizacional relevante que busca superar momentos de crises organizacionais. Esse elemento fica bastante claro, quando a seguinte frase junto a uma foto 
do diretor-presidente é estabelecida para apresentar a estória: “Acreditamos na legitimidade da retomada da empresa" (SAMARCO, 2017k).

Além disso, nessa estória a Samarco se apresenta como herói e vítima de uma injustiça, conforme busca pontuar sua importância para a região que atua e para o país, na medida em que ressalta a possível ocorrência de

[...] um efeito dominó que impacta a sociedade. Há diminuição da oferta de empregos e queda de arrecadação municipal que afetam, direta ou indiretamente, o comércio e serviços das regiões. Isso pode gerar falta de perspectiva nas pessoas e nas empresas, provocando a necessidade de mudanças geográficas, reduzindo a circulação de riquezas e dificultando o desenvolvimento das comunidades (SAMARCO, 2017k).

Em encontro aos elementos apontados por O’Neill (2002) da estória épica, a Samarco posiciona-se como uma heroína, vítima de uma injustiça, pois é impossibilitada de voltar a operar. E caso consiga voltar, logo a empresa leva consigo toda uma comunidade, uma região e um país. É a Samarco o grande lastro econômico de uma região (SAMARCO, 2017k). Além disso, elementos de drama se apresentam ao passo que a empresa alude aos efeitos desastrosos que podem ocorrer caso não volte a operar, tal como o efeito dominó que poderá impactar a sociedade. Nessa estória, a Samarco é colocada como personagem central: nenhuma outra organização, ou nenhuma outra solução, seria capaz de possibilitar desenvolvimento local-regional-nacional em termos econômicos como a Samarco faz. Assim, todos são "reféns" de sua operação (SAMARCO, 2017k).

Fica claro que a estória épica construída pela Samarco vai ao encontro dos elementos proposto por O'Neill (2002), sendo o principal objetivo superar um momento de crise organizacional provocado por um evento inesperado: o rompimento na Barragem de Fundão em Mariana.

\section{CONSIDERAÇÕES FINAIS}

O trabalho aqui apresentado analisou a tipologia do Storytelling proposta por O’Neill (2011) na produção discursiva da empresa de Mineração Samarco pós-rompimento na Barragem de Fundão. Primeiramente, ao entender as organizações como naturalmente contraditórias, a produção de eventos inesperados, que rompem com o fluxo de sentido ordinário, capaz de garantir estabilidade e continuidade das atividades organizacionais, é uma questão relevante para o contexto do estudo das organizações. As narrativas, por sua vez, ao serem entendidas como o elemento central da existência humana, são os elementos que permitem a aproximação e a compreensão do fenômeno sob análise.

Diante deste contexto, partindo da tipologia de O’Neill (2011), compreendeu-se que toda a produção discursiva revelada ao grande público pela Samarco desde a data do rompimento constituise em um grande movimento de storytelling. Os fragmentos textuais, quando olhados em conjunto 
apresentam, como um todo, uma estória épica de uma organização acometida por uma tragédia, um acidente ambiental, e que desde então luta, fazendo o que deve ser feito, para volta a operar para que assim possa, finalmente, voltar a beneficiar um sem número de pessoas, dada a sua inegável importância econômica ${ }^{7}$ Utilizando-se dos recursos narrativos, constrói uma narrativa, quase nos moldes dos contos de fada, em que os textos podem refletir aquilo que o narrador que detém o controle do encadeamento narrativo - no caso pesquisado, a Samarco como narradora - deseja que a audiência compreenda de todo o movimento gerado pela instabilidade.

Pode-se discutir ainda que, no caso estudado, os fragmentos narrativos produzidos pela Samarco compõem uma grande narrativa que pode ser reconstruída pelos autores desse trabalho (os quais também se colocam no papel de narradores ao compor o texto de apresentação dos resultados da pesquisa). Nessa grande narrativa, ${ }^{8}$ pode-se observar que figuraram elementos de todos os tipos de estórias propostas por O’Neill (2011), mas que, no todo, o caráter épico da grande narrativa fica evidente. Se o início dessa grande narrativa a estória descritiva teve grande importância para buscar delimitar a situação e abrir o escopo em relação a diversos elementos da ocasião, sem que se tomasse uma posição clara, logo em seguida a estória narcisista vem para demarcar o grande personagem de toda a estória e racionalizar os comportamentos adotados. A estória de script, por sua vez, carregada da tentativa de garantir estabilidade e certeza, recontada várias vezes, fez parte de todo o movimento narrativo, evocando o papel do grande personagem (Samarco) como mobilizadora de recursos, consciente de suas responsabilidades e "capaz de fazer o que deve ser feito". Por fim, o grande final épico que traz cara, cor e nome para a Samarco, na voz de seu novo presidente e que deixa claro o intento de todo o movimento narrativo: a busca pela retomada (legítima) das operações da empresa.

Desta maneira, pode-se perceber que, ao se observar o movimento narrativo criado por uma organização na tentativa de influenciação de sentidos e significados de um evento inesperado e suas consequências que caracterizaram um desastre, as estórias (e as características de seu tipo específico) são finamente articuladas a fim de garantir o caráter épico e heroico, afinal, diante de um desastre corporativo nas proporções do protagonizado pela Samarco, não se pode esperar nada menos que a salvação pelas mãos de um grande herói. Não se pode esquecer, porém, que as histórias não são controladas somente por aqueles que as criam e escrevem, contamos com uma audiência composta por agentes cognoscíveis e reflexivos capazes de co-criar esse movimento e, parece estar aí, a grande

\footnotetext{
${ }^{7} \mathrm{O}$ excerto em itálico representa um recurso narrativo desenvolvido pelos pesquisadores para resumir a estória épica que ficou delineada a partir de todos os excertos analisados a partir da análise cronológica dos textos e seus conteúdos.

${ }^{8}$ Ao utilizar o termo "grande narrativa" está-se referindo à estória que pode ser composta desde o rompimento até o final da coleta de dados a partir dos fragmentos narrativos produzidos pela Samarco.
} 
beleza da resistência que pode existir diante dos discursos monocromáticos e por vezes totalitários que vêm de algumas organizações.

\section{REFERÊNCIAS BIBLIOGRÁFICAS}

AILON, G. From superstars to devils: The ethical discourse on managerial figures involved in a corporate scandal. Organization. v. 22, p. 78-99, 2015.

BETTELHEIM, B. A psicanálise dos contos de fada. Rio de Janeiro: Paz e Terra, 2002.

BOJE, D. M.; ROSILE, G. A. Life imitates art: enron's epic and tragic narration. Management Communication Quartely, v. 17, n.1, p. 85-125, 2003.

BUNDY, J.; PFARRER, M. D.; SHORT, C. E.; COOMBS, W. T. Crises and Crisis Management: Integration, Interpretation, and Research Development. Journal of Management, v. 20, n. 10, 2016, p. 1-32.

DE LA VILLE, V.; MOUNOUD, E. A narrative aproach to strategy as practice: strategy making from texts and narratives. In: GOLSORKHI, D.; ROULEAU, L.; SEIDL, D.; VAARA, E. (ed.). Cambridge Handbook of Strategy as Practice - 2st Edition. Cambridge et. al.: Cambridge University Press, 2015.

FISHER, W. R. Narration as a human communication paradigm: the case of public moral argument. Communication Monographs, v. 51, n. 1, 1984.

GOVERNO DE MINAS GERAIS. Avaliação dos efeitos e desdobramentos do rompimento da barragem de Fundão em Mariana-MG. Secretaria de Estado de Desenvolvimento Regional, Política Urbana e Gestão Metropolitana - Governo de Minas Gerais, Belo Horizonte, 2016.

KOPP, D. M.; NIKOLOVSKA, I.; DESIDERIO, K. P.; GUTERMAN, J. T. "Relaax, I remember the recession in the early 1980's...." Organizational Storytelling as a crisis management tool. Human Resource Development Quartery, v. 22, n. 3, 2011.

MAITLIS, S.; SONENSHEIN, S. Sensemaking in Crisis and Change: Inspiraton and Insights from Weick (1988). Journal of Management Studies, v. 47, n. 3, 2010, p. 551-580.

MCFARLANE, A.; NORRIS, F. Definitions and concepts in disaster research. EM: NORRIS, F.; GALEA, S.; FRIEDMAN, M.; WATSON, P. (Eds.). Methods for disaster mental health research. New York: Guilford Press, p. 3-19, 2006.

MITTINS, M.; ABRATT, R.; CHRISTIE, P. Storytelling in reputation management: the case of Nashua mobile south Africa. Management Decision, v. 49, p. 405-421, 2011.

MODENA, C. M.; HELLER, L. Desastre da Samarco: aproximações iniciais. Ciência \& Cultura, v. 68, n.3, 2016.

O'NEILL, J. W. The role of storytelling in affecting organizational reality in the strategic management process. Journal of Behavioral and Applied Management, v. 4, n.1, p. 3-15, 2002.

ROULEAU, L. Studying strategizing through narratives of practice. In: Golsorkhi, D.; Rouleau, L.; Seidl, D.; \& Vaara, E. (eds.). Cambridge Handbook of Strategy as Practice - 2st Edition. Cambridge University Press, 2015. 
SAMARCO MINERAÇÃO. Laudos garantem potabilidade da água tratada em Colatina. Publicado em: 28/11/2015. Disponível em: http://www.samarco.com/noticia/comunicado-74/. Acesso em: ago. 2017a.

SAMARCO MINERAÇÃO. A água em Colatina é segura e própria para o consumo e uso doméstico. Publicado em: 11/12/2015. Disponível em: http://www.samarco.com/noticia/a-agua-emcolatina-e-segura-e-propria-para-o-consumo-e-uso-domestico/. Acesso em: ago. 2017b.

SAMARCO MINERAÇÃO. Laudos do CPRM e da ANA atestam a qualidade da água do Rio

Doce. Publicado em: 17/12/2015. Disponível em: http://www.samarco.com/noticia/laudos-do-cprme-da-ana-atestam-a-qualidade-da-agua-do-rio-doce/. Acesso em: ago. 2017c.

SAMARCO MINERAÇÃO. Samarco apoia e capacita equipes das estações de tratamento. Publicado em: 29/12/2015. Disponível em: http://www.samarco.com/noticia/samarco-apoia-ecapacita-equipes-das-estacoes-de-tratamento/. Acesso em: Agosto, $2017 \mathrm{~d}$.

SAMARCO MINERAÇÃO. A Samarco e a Economia. Disponível em: http://www.samarco.com/samarco-e-a-sociedade/. Acesso em: ago. 2017e.

SAMARCO MINERAÇÃO. Estudo mostra impacto da paralisação da Samarco na economia. Publicado em: 28 de março de 2017. Disponível em: http://www.samarco.com/noticia/estudomostra-impacto-da-paralisacao-da-samarco-na-economial. Acesso em: ago. 2017f.

SAMARCO MINERAÇÃO. Fazer o que deve ser feito. Esse é o nosso compromisso. Publicado em: 04 de Dezembro de 2015. Disponível em: http://www.samarco.com/ noticia/comunicado-91/. Acesso em: ago. $2017 \mathrm{~g}$.

SAMARCO MINERAÇÃO. Retorno das operações da Samarco é tema de audiência pública no Espírito Santo. Publicado em: 5 de maio de 2016. Disponível em: http://www.samarco.com/wpcontent/uploads/2016/08/05-05-2016-Retorno-das-operacoes-da-Samarco-e-tema-de-audienciapublica-no-Espirito-Santo.pdf. Acesso em: Agosto, 2017h.

SAMARCO MINERAÇÃO. Retomada das operações da Samarco é tema de audiência pública. Publicado em: 23 de maio de 2017. Disponível em: http://www.samarco.com/noticia/retomada-dasoperacoes-da-samarco-e-tema-de-audiencia-publica/. Acesso em: ago. 2017j.

SAMARCO MINERAÇÃO. Artigo: queremos voltar a operar. Publicado em: 30 de maio de 2017. Disponível em: http://www.samarco.com/noticia/artigo-queremos-voltar-operar/. Acesso em: ago. 2017k.

SODERBERG, A. Sensegiving e sensemaking in an integration process: A narrative approach to the study of an international acquisitions. In: CZARNIAWSKA, B.; GAGLIARDI, P. Narratives we organize by. John Benjamins Publishing: PA, 2004.

SONENSHEIN, S. We're changing or are we? Untangling the role of progressive, regressive and stability narratives during strategic change implementation. Academy of Management Journal, v. 53, p. 477-512, 2010.

STAKE, R. E. Qualitative Research: Studying How Things Work. New York: The Guilford Press, 2010.

SUTCLIFFE, K. M.; CHRISTIANSON, M. K. Managing for the unexpected. Michigan Ross school of Business: Ross thought in action, 2013.

VALDEBENITO, M. S. Image repair discourse of chilean companies facing a scandal. Discourse \& Communication, v. 7, p.1, p. 95-115, 2013.

WEICK, K. E.; SUTCLIFFE, K. M. Managing the Unexpected: Resilient performance in na age of uncertainty 2nd Ed. San Francisco: HB Printing, 2007. 